\title{
Grupos de comercialização de etanol e governança em rede
}

\section{Ethanol trading groups and network governance}

\author{
Dalton Siqueira Pitta Marques ${ }^{1}$ \\ Luiz Fernando de Oriani e Paulillo \\ Carlos Eduardo de Freitas Vian ${ }^{3}$
}

\begin{abstract}
Resumo: Embora um dos mais importantes da economia brasileira, o setor sucroalcooleiro é pouco estudado no que se refere às transações entre os elos de produção e distribuição. Este trabalho avança nesta temática, com foco especial nos grupos de comercialização de etanol, uma iniciativa das usinas para venda conjunta de sua produção, que adquire características de redes de empresas. Desta forma, este artigo tem como objetivo mostrar os modos de organização de diferentes grupos de comercialização de etanol e os mecanismos de governança constituídos para a venda do produto. Para isso, foram realizados estudos de caso com três grupos atuantes na região Centro-Sul do Brasil, que indicaram que os grupos caracterizam uma governança em rede multifacetada e que altera as dinâmicas das transações e os fluxos de informações entre os atores. Os grupos não se restringem aos intermediários das transações entre usinas e distribuidoras; eles criam uma nova dinâmica, propiciando melhor acesso ao mercado, sinalizando preços, administrando contratos e organizando arranjos logísticos.
\end{abstract}

Palavras-chave: Redes de empresas. Governança das transações. Setor sucroalcooleiro. Etanol. Grupos de comercialização.

\begin{abstract}
Although being one of the most important economic industry, the Brazilian sugar and ethanol industry is scarcely studied with regard to transactions between production and distribution actors. This article deepens the study of this topic focusing on ethanol trading groups, an initiative of ethanol manufacturers for joint sale exhibiting characteristics of company networks. Therefore, this study aims to show the forms of organization of the ethanol trading groups and their governance mechanisms. Case studies were conducted with three groups operating in the Mid-south region of Brazil indicating a multi-faceted network governance, which changes the dynamics of transactions and the information flow between the actors. The trading groups play the role of transactions' intermediaries, and they also create a new dynamics providing better access to markets, promoting price signaling, managing contracts, and organizing logistic arrangements.
\end{abstract}

Keywords: Network of companies. Transaction governance. Sugar and ethanol industry. Trading groups.

\section{Introdução}

A agroindústria sucroalcooleira brasileira é complexa, pois objetiva a produção e a venda de dois produtos estratégicos: o açúcar, uma fonte alimentar de primeira necessidade em todo o mundo, essencial para a segurança alimentar; e o álcool, estratégico no abastecimento do mercado de combustível para automóveis no mercado interno, além de seus usos industriais (PAULILLO; MELLO; VIAN, 2006, p. 69). Um ponto de inflexão no setor ocorreu na metade da década de 1970, com o Proálcool, que consolidou o setor como fonte de energia, mediante forte intervenção do Estado (PAULILLO et al., 2007). Em fins da década de 2000, o Brasil se consolidou como o maior produtor mundial de açúcar e o segundo maior de álcool. A cana-de-açúcar (por meio do etanol e da energia elétrica produzida a partir da queima do bagaço), em 2009 foi responsável por 18\% da energia consumida no Brasil (JANK, 2010).

Na década de 2000, se acentuou um processo de fusões e aquisições, acompanhado pela entrada cada vez maior do capital internacional. Conforme Vian, Lima e Lima (2008), sobretudo no Estado de São Paulo,

\footnotetext{
${ }^{1}$ Fundação Armando Álvares Penteado - FAAP, Av. Independência, 3670, CEP 14026-160, Ribeirão Preto, SP, Brasil, e-mail: dsmarques@faap.br

2 Departamento de Engenharia de Produção, Universidade Federal de São Carlos - UFSCar, Rod. Washington Luis, Km 235, CEP 13560-000, São Carlos, SP, Brasil, e-mail: dlfp@ power.ufscar.br

${ }^{3}$ Escola Superior de Agricultura Luiz de Queiroz - ESALQ, Universidade de São Paulo - USP, Av. Pádua Dias, 11, CEP 13418-900, São Carlos, SP, Brasil, e-mail: cefvian@esalq.usp.br
}

Recebido em 4/10/2011 — Aceito em 25/5/2012

Suporte financeiro: CNPq. 
embora tenha ocorrido uma desconcentração técnica (surgimento de novas unidades em detrimento do aumento de moagem de unidades existentes), houve uma elevação da centralização de capitais. Sobre a internacionalização do setor, levantamento do Banco Central indicou que, entre janeiro de 2007 e junho de 2009, o Brasil recebeu US\$ 3,1 bilhões de investimentos estrangeiros na indústria do etanol (BARROS, 2010). Apesar das fusões e aquisições, a agroindústria do açúcar e do álcool ainda é muito pulverizada, conforme mostrou Siqueira e Castro Junior (2010): os quatro maiores grupos industriais não concentravam, em 2009, mais do que $32 \%$ do mercado. Por sua vez, as quatro maiores distribuidoras concentravam $57 \%$ do mercado de etanol (AGÊNCIA..., 2010).

Se atualmente há uma discrepância entre a concentração nos setores de produção e distribuição, no período de desregulamentação, em fins da década de 1990, ela era ainda mais gritante. No período que antecedeu à chegada do livre mercado, as usinas acusavam as distribuidoras de formação de cartel para depreciação do preço, enquanto as distribuidoras defendiam a liberalização total da comercialização como condição para competir com empresas que operavam no mercado negro. Segundo Vian (2003), quando se instituiu o livre mercado, eram mais de 300 empresas ofertando álcool para cinco grandes distribuidoras de combustíveis. Isto, somado à queda no consumo do combustível, fez com que o preço do litro recebido pela usina despencasse de aproximadamente $\mathrm{R} \$ 0,41$, para $\mathrm{R} \$ 0,16$ em maio de 1999.

Para lidar com esse cenário, perto de 170 indústrias se juntaram, à época, para formar a Brasil Álcool e a Bolsa Brasileira de Álcool (BBA), com o objetivo de enxugar estoques e concentrar a venda do etanol. Com $85 \%$ da produção do Centro-Sul do país, as usinas conseguiram elevar os preços. A dificuldade de coordenar um grande número de empresas (era frequente a venda, a preços menores, por fora do grupo para fazer caixa rapidamente) e a decisão do CADE (Conselho Administrativo de Defesa Econômica), contrária à concentração das empresas, fizeram com que a iniciativa não perdurasse (VIAN, 2003; MELLO, 2004). A iniciativa, porém, deu frutos. Unidades se uniram em grupos menores para se fortalecer na negociação com distribuidoras, que historicamente vinham impondo preços baixos (VIAN, 2003). A aglutinação em torno de pools representava a possibilidade de maior remuneração para as empresas (PAULILLO; VIAN; MELLO, 2008) e é provável que refletisse uma estratégia para aumentar seu poder de negociação com as distribuidoras (MORI; MORAES, 2007). Conforme Vian, Paulillo e Belik (2008), mesmo com a existência dos grupos de comercialização, a relação entre distribuidoras e usinas ainda não é das mais estáveis.
Os grupos de comercialização se fortaleceram e, na safra 2006/2007, estima-se que 51,48\% do álcool produzido no Centro-Sul do país tenha saído das indústrias pelos quatro grupos de comercialização que atuavam na região: Bioagência, Copersucar, CPA e SCA (DOLNIKOFF, 2008). Em setembro de 2008 foi criado um quinto grupo: Allicom. Dele faziam parte dois gigantes: Usina São João e São Martinho (VALOR..., 2009). Em maio de 2009, foi anunciada a criação do Brasil EBC, formado por unidades do Oeste Paulista e do Mato Grosso do Sul (UNIÃO..., 2009). No entanto, a Allicom foi destituída em agosto de 2011 e a Brasil EBC, segundo informações do setor, nunca chegou a concretizar sua atuação comercial; mostrando que a coordenação das usinas não é tarefa trivial.

Os grupos do Centro-Sul do Brasil diferem entre si no tamanho, na constituição jurídica, nos procedimentos de venda e nos serviços. Porém, ainda que haja particularidades, a associação horizontal de empresas, com certo grau de articulação e uso compartilhado de serviços e informações, é fator comum. Essas características dão indício da presença de redes para governar as transações entre indústrias e distribuidoras de etanol. Conforme Sacomano Neto e Truzzi (2004), o grande número de fusões, alianças estratégicas e joint ventures mostra a importância da perspectiva de redes para explicar as novas relações entre atores econômicos. Coloca-se, assim, o seguinte problema para esta pesquisa: As organizações de unidades produtoras de etanol em grupos de comercialização podem ser caracterizadas como redes? O objetivo do artigo é mostrar os modos de organização de diferentes grupos de comercialização de etanol e os mecanismos de governança constituídos para venda do produto. Por modos de organização entendem-se elementos como critérios de entrada e saída, formas de associação, serviços prestados e estruturas de apoio. A governança compreende categorias como mecanismos de comercialização, frequência e responsabilidades sobre especificidades das transações.

Paulillo, Mello e Vian (2006, p. 70) destacam que

[...] a formação de pools de comercialização de etanol por parte de industriais localizados na região Centro-Sul do país constitui um fator organizacional importante na nova estrutura de governança pós-desregulamentação estatal [...].

Apesar disso, os estudos que colocam a governança como temática central para analisar o setor sucroalcooleiro tradicionalmente se concentraram em estudar as relações entre produtores de cana e indústrias (CARVALHO et al., 1993; NEVES; WAACK; MARINO, 1998; MATOS; MELO; MATOS, 1999; AMARAL; NEVES; MORAES, 2003; SOUZA, 2004; CONSOLI, 2007; BACCARIN; GEBARA; FACTORE, 2009). Só recentemente passou-se a 
olhar para o elo indústria-distribuição. Um desses trabalhos foi desenvolvido por Dolnikoff (2008), que analisou a racionalidade da decisão de usinas e distribuidoras de combustíveis ao optarem por uma estrutura de governança. Outra exceção é Lopes (2009), que descreveu como estão estruturados os canais de distribuição de etanol, desde as indústrias até os postos de combustíveis, e como se dão as transações no mercado formal. Em ambos os trabalhos, porém, os grupos de comercialização não são vistos como uma forma particular de governança, mas como um agente intermediário, cujas transações podem se dar via mercado spot ou contratos. Lopes (2009, p. 93), porém, relativiza ao afirmar que, com a crescente demanda por etanol no mercado doméstico, as estruturas de governança tenderiam a passar por transformações que minimizassem os custos de transação.

O presente trabalho mostra que essas transformações que objetivam minimizações dos custos de transação das empresas produtoras de etanol no setor sucroenergético brasileiro incluem um espectro de ações mais amplas do que a economia institucional considera, conforme Scott (2001), Powell (1990), Podolny e Page (1998), Jones, Hersterly e Borgatti (1997) e Ménard (2004). Essas ações emergem no setor sucroenergético brasileiro com as ações dos grupos de comercialização de etanol, que incluem: o uso de regras formais para moldar relacionamentos; compartilhamentos de recursos financeiros e organizacionais; relações de cooperação; coordenações desenvolvidas por unidades coordenadoras grupais; engajamentos de indivíduos em ações recíprocas, preferenciais e de apoio mútuo com reuniões periódicas, etc.

$\mathrm{O}$ item 2 apresenta a discussão teórica que embasou este trabalho, ancorada em duas abordagens teóricas do estudo de redes, conforme categorização de Powell e Smith-Doerr (1994): primeiramente, discute-se a rede como ferramenta analítica, usada para estudar relações sociais, entre empresas ou mesmo pessoas; depois, discute-se a rede como estrutura de governança; uma forma de coordenar as relações entre atores econômicos. No item 3, explicitam-se os procedimentos metodológicos, ancorados em um estudo de casos múltiplos. O item 4 apresenta de maneira sucinta cada um dos casos para, em seguida, de maneira detalhada, compará-los entre si e à luz da teoria. Por fim, no item 5, com as considerações finais, retoma-se o objetivo do trabalho, destacando-se os méritos da pesquisa, suas limitações e sugestões de estudos futuros.

\section{Referencial teórico}

\subsection{Redes de empresas}

A relevância do conceito de rede advém da sua capacidade de captar a crescente sofisticação das relações entre empresas (GRANDORI; SODA,
1995; BRITTO, 2002). Na cadeia do etanol, essa sofisticação pode ser observada no seguinte fenômeno: as indústrias sucroalcooleiras concorrem entre si, ao mesmo tempo que podem cooperar para criar melhores condições de competição na relação com as distribuidoras (como representado pelos grupos de comercialização), da mesma forma que todos os elos da cadeia podem cooperar em defesa do etanol frente a outras fontes de energia. Farina e Zylbersztajn (2003) afirmam, porém, que o conceito de rede não deve ser confundido com o de sistemas coordenados ou cadeias. As redes incluem entidades interdependentes, com geração de externalidades de rede. Além disso, há a delegação de direitos de decisão, que permitem estratégias e ações coletivas, mas exigem cooperação e compromisso. Já sistemas coordenados de produção têm o predomínio de interdependência vertical, com uma organização líder que possui poder de compra e direitos de decisão residual, e não geram externalidades de rede.

Conforme Assens (2003, p. 50), ainda que diferentes questões sejam consideradas, de acordo com o ângulo de análise (econômico, sociológico ou territorial) de uma rede, há características que são essenciais e invariáveis. Primeiramente, uma rede é composta por nós, ou pontos de interconexão, que possibilitam a realização de trocas comerciais ou o fluxo de informações. Os nós são ligados por conexões que traduzem a natureza das trocas, sua periodicidade, sua densidade, etc. Cada nó tem uma posição, de acordo com as funções assumidas perante os outros membros da rede. Assim, o conceito de rede repousa sobre os seguintes princípios imutáveis: 1. autonomia dos nós (que têm liberdade de ajustar seu comportamento e suas decisões); 2. interdependência dos nós (que, a despeito de sua heterogeneidade, se unem por um denominador comum); 3. separação dos nós (seja por distâncias tangíveis - espaço, território - ou intangíveis - tempo, identidade e história).

Britto (2002, p. 349) cita outras características das redes de empresas, muitas das quais em consonância com as acima apresentadas: grau elevado de compatibilidade e complementaridade técnica entre os agentes e as atividades por eles realizadas; alta integração de atividades produtivas, devido à presença de externalidades técnicas, pecuniárias e de demanda; geração de externalidades tecnológicas; consolidação de uma infraestrutura particular para suportar a rede e que implica certo compartilhamento de investimentos.

Embora haja características comuns, pode haver redes com formas de organização muito diferentes umas das outras. Balestrin e Vargas (2004), partindo de modelo conceitual estabelecido por Marcon e Moinet (2000), complementado com evidências de outros estudos, criaram uma classificação para as redes: Verticais, com estrutura hierárquica, cujas 
relações são semelhantes àquelas entre matriz e filial; Horizontais, constituídas por empresas independentes, mas que optam por coordenar algumas atividades de forma conjunta (seja para suportar riscos de desenvolvimento de tecnologias, seja para ações mercadológicas); Formais, com forte dimensão contratual que estabelece regras de conduta entre os atores; Informais, com base na convivência cujo objetivo é trocar experiência e informação, sem qualquer tipo de contrato formal, agindo conforme a confiança e interesses mútuos.

A formação de uma rede de empresas é motivada tanto por fatores restritivos externos, que as levam a se agruparem de maneira reativa a adversidades, quanto por um movimento proativo, para obter vantagens competitivas (ASSENS, 2003). A respeito dos fatores restritivos, Mazzali e Costa (1997) colocam que as redes são capazes de edificar uma "zona de estabilidade", com a redução do risco associado a um universo turbulento. Entre as vantagens competitivas obtidas por meio de estruturas em rede, há as externalidades, como já citado. Essas externalidades podem ser: técnicas, que geram modificações nas características das respectivas funções de produção; tecnológicas, nas quais há mudança no ritmo de adoção e difusão de inovações; de demanda, com uma interdependência na demanda entre unidades; e pecuniárias, que dão origem a mudanças nos preços relativos dos fatores e em modificações nas estruturas de custos (BRITTO, 2002). Quando as empresas possuem clientes ou canais de distribuição comuns (como as unidades produtoras de etanol), o compartilhamento de relações com o mercado pode trazer também vantagens de custo (MARCHI; WITTMANN, 2008).

Ainda, conforme Balestrin, Vargas e Arbage (2007), evidências empíricas indicam que um dos grandes motivos para a formação de redes interorganizacionais reside no fato dessas terem se mostrado uma forma eficiente de governança das relações econômicas. Por isso, discute-se a seguir a rede como estrutura de governança particular, com características próprias quando comparada a mercado, contratos ou hierarquia, formas de governança tradicionalmente identificadas pela Economia dos Custos de Transação.

\subsection{Governança em rede}

Powell (1990) posiciona as redes, tipificadas por padrões recíprocos de comunicação e trocas, como uma governança alternativa ao mercado e à hierarquia. Ao mesmo tempo, considera as redes como uma forma mais complexa de governança do que o simples estabelecimento de contratos. A novidade do trabalho de Powell estava em construir uma argumentação a favor da rede como um arranjo organizacional distinto, em oposição a formas intermediárias que combinam mercado e hierarquia. Podolny e Page (1998, p. 59), definem a governança em rede como

[...] um conjunto de dois ou mais atores que buscam, repetidamente, estabelecer relações de troca entre si e, ao mesmo tempo, carecem de uma autoridade organizacional legítima para arbitrar e solucionar disputas que podem surgir durante as transações [...].

Os autores contestam Williamson (1985), ao afirmar que a governança em rede não pode ser reduzida a uma simples hibridização das formas mercado e hierárquica, pois na rede há uma ética de confiança e nessas duas os atores têm postura mais adversária.

Jones, Hersterly e Borgatti (1997, p. 914) definem a governança em rede como:

[...] um conjunto selecionado, persistente e estruturado de firmas autônomas (assim como agências não lucrativas) engajadas em criar produtos ou serviços baseados em contratos implícitos e abertos para adaptar às contingências ambientais e coordenar e salvaguardar transações. Esses contratos são socialmente - não legalmente - amarrados.

O termo "selecionado" indica que as empresas formam um subconjunto dentro do setor, no qual as empresas transacionam frequentemente entre si, mas raramente com membros externos. O termo "persistente" significa que não se tratam de transações esporádicas: os membros trabalham repetidamente entre si ao longo do tempo. "Estruturado" indica que as transações dentro da rede não são nem randômicas, nem uniformes, mas têm um padrão que reflete uma determinada divisão do trabalho. Por "contratos implícitos e abertos", entende-se que a adaptação, a coordenação e as salvaguardas das transações não são derivadas de estruturas autoritárias ou contratos legais. Estes últimos até podem existir, mas não definem as relações entre todas as partes. $\mathrm{O}$ uso de mecanismos sociais para solução de problemas, ao invés da autoridade, de recursos legais ou de regras burocráticas, é que contribuem para o sucesso da forma de governança em rede.

As redes são complexas: não envolvem nem os critérios explícitos do mercado, nem o paternalismo da hierarquia. As transações ocorrem por meio de indivíduos engajados em ações recíprocas, preferenciais e de apoio mútuo. Unidades individuais existem não por elas mesmas, mas em relação com outras unidades. A rede é vista como a cola social que mantém os indivíduos juntos em um sistema coerente (POWELL, 1990). Grandori e Soda (1995), posteriormente, afirmaram que os atributos da rede não são necessariamente intermediários àqueles da hierarquia e do mercado, mas também não precisam ser 
únicos: há, sob diferentes combinações e intensidades, elementos presentes nas outras formas de governança.

Ménard (2004) apresenta as redes de empresas como uma entre várias formas híbridas, que são os mecanismos de governança situados entre a hierarquia e o mercado. Segundo Ménard (1997, 2004), o que distingue as formas híbridas de governança é a combinação entre competição e cooperação, que se sobrepõe ao papel central exercido pelo preço no mercado spot e pelo comando na hierarquia. Ménard (2004, 2005), por meio da análise de diversos estudos, destacou características que são comuns às formas híbridas de organização, dentre as quais as redes relacionais de empresas. A primeira delas é o compartilhamento de recursos. A segunda é a existência de contratos relacionais, que buscam assegurar o relacionamento entre os parceiros e não apenas o fornecimento de produtos. A terceira característica é a relação de competição, com um misto de interdependência e autonomia, na qual os agentes competem dentro do arranjo estabelecido, mas também com outros arranjos. $\mathrm{O}$ autor resume as condições que favorecem o desenvolvimento das formas híbridas, ao afirmar que elas se desenvolvem quando investimentos específicos:

[...] podem se estender sobre parceiros sem perder as vantagens da autonomia, enquanto há incertezas suficientes para tornar o compartilhamento uma alternativa desejável. É a combinação desses dois elementos que importa. Se somente um atributo estiver presente, a governança tende para arranjos baseados em contratos. Quando os dois atributos se combinam, a governança se torna mais autoritária. Dessa forma, é a combinação entre oportunismo, ou risco de oportunismo, e falta de coordenação, ou risco de falta de coordenação, que determina a governança por formas híbridas (MÉNARD, 2005, p. 299).

Ainda sobre as condições que induzem a cada uma das formas híbridas (confiança, rede relacional, liderança ou autoridade formal), Ménard (2004) utiliza como referência o modelo proposto por Williamson (1994), segundo o qual o grau de especificidade dos ativos e os custos de transação determinam a estrutura de governança mais adequada. Ménard, porém, dá um passo além desse modelo e introduz a incerteza, especialmente relacionada a problemas de coordenação e oportunismo, como fator determinante. Ainda que Williamson considere que a frequência das transações possa gerar reputação, em sua obra, a incerteza e o oportunismo têm pouca importância para determinar a governança. No modelo expandido por Ménard, quanto maior a incerteza, mais propícias tornam-se as estruturas de governança com maior centralidade (estando no seu extremo a autoridade formal).
Para Jarillo (1988), a rede é o arranjo mais efetivo quando os custos de se adquirir no mercado são menores do que os de se fazer internamente e quando há possibilidade de reduzir os custos de transação comparativamente à aquisição no mercado. A rede traz os benefícios da integração vertical e do compartilhamento de experiência entre os atores, sem necessitar de investimentos financeiros excessivos e sem os efeitos negativos, como a perda de eficiência, de uma estrutura burocrática. Na visão de Powell e Smith-Doerr (1994), a rede permite a obtenção de economias de escala e de escopo, que são ganhos comuns a formas hierárquicas de governança, com uma grande vantagem sobre essas: são mais facilmente alteradas. Assim, a flexibilidade com que permite a recombinação de seus elementos é uma grande vantagem da governança em rede, embora a coordenação não seja um processo simples (SACOMANO NETO; TRUZZI, 2004, p. 25). É justamente a autonomia dos membros e a complexidade dos processos decisórios que torna a coordenação complexa.

A partir das discussões acima, foram definidos indicadores, conforme Quadro 1, para análise do modo de organização dos grupos e da governança das transações entre o setor de produção e distribuição de etanol, resultante da presença dos grupos de comercialização. Esses indicadores, compilados sobretudo dos trabalhos de Jarillo (1988), Powell (1990), Ménard (1997, 2004, 2005) e Podolny e Page (1998), balizaram a construção dos instrumentos de coleta de dados. Detalhes sobre os procedimentos metodológicos são apresentados a seguir.

\section{Procedimentos metodológicos}

A pesquisa de campo teve início, após a construção de um referencial teórico básico, com a realização, no primeiro semestre de 2009, de uma entrevista semiestruturada, de cunho exploratório,

Quadro 1. Indicadores para análise da governança.

\begin{tabular}{|l|}
\hline \multicolumn{1}{|c|}{ Indicadores } \\
\hline Critérios de entrada e saída \\
\hline Bases normativas \\
\hline $\begin{array}{l}\text { Mecanismos de comercialização de etanol e frequência } \\
\text { das transações }\end{array}$ \\
\hline Taxas cobradas e preços obtidos \\
\hline Responsabilidades sobre as transações \\
\hline Serviços prestados e estruturas de apoio \\
\hline Motivos para participação nos grupos \\
\hline Mecanismos de comunicação \\
\hline Cooperação entre usinas \\
\hline Tomada de decisões \\
\hline
\end{tabular}

Fonte: Elaborado pelos autores. 
com um analista estratégico de um dos grupos de comercialização de etanol atuantes na região Centro-Sul do Brasil. Esta entrevista evidenciou a necessidade de aprofundamento na teoria de redes de empresas (acima apresentada) e contribuiu para a lapidação dos instrumentos de pesquisa utilizados no estudo de casos múltiplos.

Adotou-se aqui a estratégia de estudo de caso, já que o fenômeno dos grupos de comercialização é recente e não há série de dados sobre eles. Se por um lado o estudo de caso, como método, não permite generalização estatística, por outro contribui para construção teórica do respectivo domínio do conhecimento (YIN, 1984). Além disso, optou-se por estudo de casos múltiplos, pois, conforme Voss, Tsikriktsis e Frohlich (2002), ao abordar mais de um caso, aumenta-se a validade externa e evita-se viés. Foram estudados três casos, número relevante, considerando-se que são quatro os grupos estruturados que atuam no Centro-Sul. Além disso, como característico de estudos de caso, usou-se neste trabalho de abordagem qualitativa para coleta e análise dos dados que, comparativamente à quantitativa, traz os seguintes benefícios: ênfase no processo, forte contextualização, maior flexibilidade de trabalho, uso de fontes múltiplas de dados, maior proximidade com o objeto de estudo e melhor concepção das realidades organizacionais (BRYMAN, 1989). Vale destacar que o método de estudo de caso para pesquisas com os grupos de comercialização de etanol foi, inclusive, sugerido por Lopes (2009, p. 103), por permitir maior profundidade na análise dos arranjos entre usinas e grupos.

Por cada caso estudado, compreenda-se a empresa que coordena o grupo de comercialização e sua respectiva rede, composta pelas usinas associadas. A fim de garantir o sigilo dos que participaram do estudo, nem empresas nem respondentes foram identificados. Para coleta de dados, fez-se uso de entrevistas semiestruturadas, buscando perceber a perspectiva dos indivíduos sobre os grupos de comercialização e sobre as transações envolvendo os setores de produção e distribuição. Conforme Quadro 2, foram realizadas entrevistas com diretores das empresas coordenadoras de cada grupo de comercialização e com usinas associadas. Além disso, também se constituíram fonte de informações distribuidoras de combustíveis e entidades setoriais, permitindo a confrontação das informações. As entrevistas foram todas realizadas pessoalmente, o que possibilitou, também, a observação da infraestrutura administrativa de cada grupo. Por fim, com o intuito principal de obter dados adicionais e checar as informações obtidas nas entrevistas, foram analisados os seguintes documentos: sites dos grupos de comercialização e das usinas; apresentações, relatórios e informativos institucionais fornecidos por alguns grupos e usinas; notícias veiculadas na imprensa sobre os grupos, usinas associadas e distribuidoras de combustíveis.

Por fim, vale destacar que, até por não usar de abordagem quantitativa, os dados não foram coletados seguindo quaisquer critérios estatísticos, sendo os respondentes selecionados pelo critério de conveniência, em virtude, também, da dificuldade de se obter dados no setor. Apesar disso, os resultados podem ser considerados representativos. Foram realizadas 13 entrevistas em profundidade, com respondentes experientes e de importância reconhecida pelo setor, tanto nas coordenadoras dos grupos, quanto nas usinas e nas distribuidoras, Além disso, foram abordadas desde pequenas usinas, de gestão

Quadro 2. Fontes de dados.

\begin{tabular}{|c|c|c|c|}
\hline & Caso A & Caso B & Caso C \\
\hline Entrevistas com a coordenadora & Diretor executivo & $\begin{array}{l}\text { Diretor executivo; } \\
\text { Gerente de } \\
\text { planejamento }\end{array}$ & Diretor de comunicação \\
\hline Entrevistas com associadas & $\begin{array}{c}\text { Sócio-superintendente } \\
\text { da usina X; } \\
\text { Diretor-superintendente } \\
\text { da usina Y }\end{array}$ & $\begin{array}{l}\text { Coordenador comercial } \\
\text { e analista de mercado da } \\
\text { corporação de usinas Z; } \\
\text { Gerente comercial da } \\
\text { corporação de usinas T }\end{array}$ & $\begin{array}{c}\text { Supervisor comercial e } \\
\text { gerente de compras da } \\
\text { usina } S\end{array}$ \\
\hline Período de realização das entrevistas & $\begin{array}{l}\text { Entre dez./2010 e } \\
\text { fev./2011 }\end{array}$ & $\begin{array}{l}\text { Entre dez./2010 e } \\
\text { jan./2011 }\end{array}$ & Ago./11 \\
\hline Documentos & $\begin{array}{l}\text { Notícias e informativo } \\
\text { das usinas }\end{array}$ & $\begin{array}{l}\text { Notícias e informativos } \\
\text { das usinas }\end{array}$ & $\begin{array}{c}\text { Notícias, relatório anual } \\
\text { e código de conduta da } \\
\text { coordenadora }\end{array}$ \\
\hline Entrevistas com setor de distribuição & \multicolumn{3}{|c|}{$\begin{array}{l}\text { Gerente de compras da distribuidora W, associada ao Sindicom; Trader da } \\
\text { distribuidora K, também associada ao Sindicom; Diretor de entidade de classe. }\end{array}$} \\
\hline
\end{tabular}

Fonte: Elaborado pelo autor. 
familiar, até alguns dos maiores grupos industriais sucroalcooleiros do país.

\section{Apresentação dos casos}

Os três casos estudados têm por característica a presença de uma empresa que, além de realizar as operações comerciais, contando com uma equipe de inteligência de mercado, faz a coordenação dos grupos e oferece assessorias às usinas. É com essa empresa coordenadora que as usinas firmam os contratos de associação aos grupos, com, no entanto, diferentes níveis de formalização em cada caso. A seguir, são apresentados brevemente os perfis de cada grupo, para posterior discussão dos mecanismos de governança.

O grupo A foi criado logo após a dissolução da BBA/Brasil Álcool. Todos os fundadores continuam membros do grupo e, embora ele tenha dobrado de tamanho desde então, entre os casos estudados, é o menor em número de associados. Fusões e aquisições no setor fazem com que haja constantemente a entrada ou saída de membros. Nesse caso, por ser também formado em geral por unidades de menor poderio econômico, nos últimos anos houve perda de alguns membros, que foram adquiridos por corporações associadas a outros grupos. Fator importante para a aglutinação das empresas em torno desse grupo foi o histórico de participação em uma associação de produtores de cachaça, além de existirem muitos laços pessoais. A decisão de venda (momento, quantidade, preço e produto - hidratado ou anidro) é da usina que, porém, recebe informações da coordenadora para subsidiá-la.

O grupo B, também criado após a dissolução da BBA/Brasil Álcool, praticamente dobrou de tamanho desde então e, dentro os estudados, é o que tem maior número de associados. Esse crescimento foi motivado, sobretudo, pelo crescimento dos grupos industriais que fazem parte dele, tanto pela implantação de novas unidades quanto pela incorporação de outras usinas. Quando de sua fundação, a aglutinação das empresas nesse grupo ocorreu pelo fato de que seus principais fomentadores eram considerados "a elite do setor", tendo sido líderes do processo de criação da BBA e participado de negociações junto ao poder público; eram empresas de maior porte e sua credibilidade foi importante para atração de mais empresas. A decisão de venda do etanol também é das usinas.

$\mathrm{O}$ caso $\mathrm{C}$ tem sua criação anterior ao fenômeno BBA/Brasil Álcool. Foi nos últimos anos, porém, que viveu maior expansão: entre 2009 e 2011, o número de associados cresceu $50 \%$. A empresa coordenadora é constituída sob a forma de sociedade anônima, de propriedade das usinas. $\mathrm{O}$ grupo tem um modelo particular de governança e atuação, quando comparado aos outros dois casos. Primeiro, ele não se limita a comercializar a produção de etanol; a venda de açúcar, de eletricidade e de outros subprodutos também é de responsabilidade da coordenadora, que pode prestar esse serviço a unidades que não fazem parte do grupo. Em segundo lugar, ele possui uma grande infraestrutura, realizando a logística de distribuição, tanto no mercado doméstico, quanto em operações de exportação. Em terceiro lugar, a coordenadora garante a comercialização das usinas associadas, assumindo todas as responsabilidades do processo de venda. As usinas não participam do processo de comercialização e devem entregar toda sua produção à coordenadora. A decisão sobre momento, quantidade vendida, preço praticado em cada operação, para quem vender, tudo é decidido pela coordenadora do grupo. Se por um lado isto limita a atuação da usina no processo, de outro lhe garante um fluxo de caixa contínuo ao longo da safra, pois os pagamentos são feitos periodicamente durante o período, de acordo com a produção e independente das vendas. $\mathrm{O}$ valor recebido pelas usinas está lastreado no indicador ESALQ, sendo composto pela média dos últimos 12 meses do indicador. Ao final do ano, o resultado obtido na comercialização (inclusive ágios sobre o indicador ESALQ) e nas demais operações da coordenadora é rateado entre os associados.

O Quadro 3 mostra, de maneira sintética e comparativa, os três grupos estudados. No item a seguir, discorre-se sobre essas características, comparando-as entre si e com a teoria.

\subsection{Discussão dos resultados}

No período de desregulamentação do setor, as dificuldades financeiras, que levaram inclusive à falência muitas unidades, fizeram com que houvesse senso de urgência, entre as usinas, de que cooperação era fundamental para sobrevivência. Essa união em tempos de crise, característica de diversos setores, conforme mostrou a teoria, foi o fator propulsor da criação e/ou fortalecimento de grupos de comercialização de etanol.

Estabelece-se, desde então, um jogo de forças entre indústria e distribuição. No início, a produção era altamente pulverizada, enquanto a distribuição concentrada. Constata-se, quando se compara a queda nos preços para a usina e para o consumidor no período pré-desregulamentação, que o mercado já oscilava segundo as expectativas de liberação total do mercado. Enquanto o preço pago à usina, entre 1997 e 1998, caiu 43,9\% (VIAN, 2003, p. 106), o preço médio ao consumidor na cidade de São Paulo caiu apenas 7\%, conforme dados obtidos junto à ANP (AGÊNCIA..., 2011). Houve, por parte da distribuição, uma apropriação de lucro. Hoje, tal ação é mais difícil de ocorrer, em virtude de maior força no setor de produção, via grupos de comercialização, e de uma presença consistente de distribuidoras emergentes no mercado, que, mesmo algumas apresentando problemas 
Quadro 3. Comparação dos modos de organização e da governança dos grupos de comercialização.

\begin{tabular}{|c|c|c|c|}
\hline & Grupo A & Grupo B & Grupo C \\
\hline Critérios de entrada & $\begin{array}{l}\text { Aprovação dos } \\
\text { membros }\end{array}$ & $\begin{array}{l}\text { Aquisição de cota; } \\
\text { aprovação dos membros }\end{array}$ & $\begin{array}{c}\text { Aquisição de cota; } \\
\text { aprovação dos membros }\end{array}$ \\
\hline Critérios de saída & Não existem & $\begin{array}{l}\text { Cumprimento de } \\
\text { contrato anual }\end{array}$ & $\begin{array}{c}\text { Denúncia do contrato } \\
\text { com antecedência de } \\
5 \text { anos }\end{array}$ \\
\hline Base normativa & $\begin{array}{l}\text { Predomínio de } \\
\text { relacional sobre legal }\end{array}$ & Relacional e legal & Legal \\
\hline $\begin{array}{c}\text { Mecanismos de comercialização e } \\
\text { frequência }\end{array}$ & $\begin{array}{c}\text { Spot e contratos de } \\
\text { longo prazo; média } \\
\text { frequência }\end{array}$ & $\begin{array}{c}\text { Predomínio de } \\
\text { contratos de longo } \\
\text { prazo; alta frequência }\end{array}$ & $\begin{array}{c}\text { Predomínio de } \\
\text { contratos de longo } \\
\text { prazo; alta frequência }\end{array}$ \\
\hline Tomada de decisões & $\begin{array}{l}\text { Decisão de venda é da } \\
\text { usina }\end{array}$ & $\begin{array}{c}\text { Decisão de venda é da } \\
\text { usina }\end{array}$ & $\begin{array}{c}\text { Decisão de venda é da } \\
\text { coordenadora }\end{array}$ \\
\hline $\begin{array}{l}\text { Responsabilidade da coordenadora } \\
\text { sobre as transações }\end{array}$ & $\begin{array}{c}\text { Negociação e gestão de } \\
\text { contratos }\end{array}$ & $\begin{array}{l}\text { Negociação e gestão de } \\
\text { contratos }\end{array}$ & $\begin{array}{l}\text { Total (inclusive } \\
\text { recebimentos) }\end{array}$ \\
\hline Taxas e preços & $\begin{array}{l}\text { Usinas pagam } \\
\text { corretagem sobre } \\
\text { produção }\end{array}$ & $\begin{array}{l}\text { Usinas pagam } \\
\text { corretagem sobre } \\
\text { produção }\end{array}$ & $\begin{array}{c}\text { Usinas recebem } \\
\text { preço médio ESALQ; } \\
\text { eventual lucro do } \\
\text { período é distribuído }\end{array}$ \\
\hline $\begin{array}{l}\text { Serviços oferecidos às usinas; } \\
\text { estruturas de apoio }\end{array}$ & $\begin{array}{c}\text { Pesquisas de mercado } \\
\text { e assessorias; salas } \\
\text { de reuniões da } \\
\text { coordenadora }\end{array}$ & $\begin{array}{c}\text { Pesquisas de mercado } \\
\text { e assessorias; salas } \\
\text { de reuniões da } \\
\text { coordenadora }\end{array}$ & $\begin{array}{l}\text { Assessorias; salas } \\
\text { de reuniões da } \\
\text { coordenadora e } \\
\text { terminais logísticos }\end{array}$ \\
\hline Motivos das usinas para participação & $\begin{array}{l}\text { Preço e visão de } \\
\text { mercado }\end{array}$ & $\begin{array}{l}\text { Preço e visão de } \\
\text { mercado }\end{array}$ & $\begin{array}{l}\text { Preço e garantia de } \\
\text { fluxo de caixa }\end{array}$ \\
\hline Mecanismos de comunicação & $\begin{array}{l}\text { Informativos, contato } \\
\text { telefônico constante e } \\
\text { reuniões periódicas }\end{array}$ & $\begin{array}{l}\text { Informativos, contato } \\
\text { telefônico constante e } \\
\text { reuniões periódicas }\end{array}$ & $\begin{array}{l}\text { Informativos; reuniões } \\
\text { apenas esporádicas }\end{array}$ \\
\hline Ações de cooperação direta entre usinas & Elevadas & Elevadas & Médias \\
\hline
\end{tabular}

Fonte: Elaborado pelos autores.

de sonegação e adulteração de combustíveis, trazem concorrência para este elo e, por isso, maior liquidez.

O jogo de forças com as distribuidoras ocorre não só na disputa por um bom preço para venda, mas também no sentido de que a margem das distribuidoras não seja abusiva com reflexos sobre o consumidor final. Um preço alto ao consumidor é prejudicial à indústria, pois, graças aos automóveis bicombustíveis, resulta que o consumidor troque do etanol para gasolina no momento do abastecimento. Além de ser mais um motivo para a união das usinas em grupos de comercialização, de modo a adquirir poder de pressão sobre as distribuidoras, isso ajudaria a explicar o avanço na cadeia do etanol de usinas como a Cosan. Conforme Azevedo (2000, p. 35), a eficiência da cadeia como um todo depende de quão bem são solucionados os conflitos inerentes às relações entre fornecedores e compradores.

A análise dos pressupostos comportamentais dos agentes nas transações entre indústria e distribuição de etanol permite constatar a presença de: oportunismo das distribuidoras e racionalidade limitada das usinas no período de desregulamentação do setor; oportunismo, no período pós-desregulamentação, de distribuidoras emergentes que praticam sonegação e adulteração de combustíveis. Nesse contexto, mecanismos mais complexos de governança são mais eficientes para coordenador as transações. Deve-se somar, ainda, o turbulento ambiente institucional do setor, com a ainda forte participação estatal (seja via determinação de percentual de anidro à gasolina, via tributações ou participação da Petrobrás no setor) e alta volatilidade de preços (pela inter-relação com os preços do açúcar e falta de política de estoques), e a presença de especificidades de ativos. Conforme Ménard (2005), estariam estabelecidas então as bases para o surgimento de formas híbridas de governança (entre as quais as redes), quando investimentos específicos podem se estender sobre parceiros sem perder as vantagens da autonomia, enquanto há incertezas suficientes para tornar o compartilhamento uma alternativa desejável. Nesse sentido, os benefícios do grupo são ainda maiores para as pequenas usinas. Isoladamente, não teriam acesso ao mercado externo e atuariam pouco no mercado doméstico. A menor frequência de transações 
resultaria em uma visão limitada do setor, com grande assimetria de informações, pendendo favoravelmente às distribuidoras do Sindicom que, com grande escala, têm número elevado de transações e, portanto, acesso constante aos movimentos do mercado. $\mathrm{O}$ grupo permite que pequenas usinas mantenham-se eficientes na produção, mas com os benefícios da escala nas vendas via grupo.

Os grupos de comercialização, com usinas coordenando algumas atividades de forma conjunta, mas guardando sua independência, fazem surgir relações complexas, que se enquadram na definição de redes horizontais apresentada por Marcon e Moinet (2000) e Balestrin e Vargas (2004). Há uma coordenação mais rigorosa que a simples confiança, há regras formais moldando relacionamento e há compartilhamento de recursos, seja pelas informações trocadas ou pela consolidação da produção para atender a determinada venda de maior volume, conforme Ménard (2004). Não se pode esquecer, porém, da presença de uma autoridade formal, constituída pela coordenadora do grupo. No caso C, essa autoridade é, inclusive, detentora das decisões relativas às vendas. A presença de uma autoridade em redes já havia sido destacada por Grandori e Soda (1995). Os autores listaram também, como característicos da governança em rede, a presença de mecanismos de planejamento e controle (como a elaboração de estudos de mercado e reuniões entre associados), infraestrutura e equipe comum de serviços, igualmente observados nos grupos de comercialização.

Desta forma, caracteriza-se uma governança em rede na distribuição de etanol, em que os grupos exercem um papel maior do que apenas intermediários para vendas spot ou contratual. Eles são capazes de alterar a dinâmica do setor e melhorar o poder de barganha das usinas diante das distribuidoras, lembrando-se que, por barganha, não se entende apenas a negociação de preços, mas de todos os termos de uma relação (AZEVEDO, 2001). No Quadro 4, são resumidos os benefícios dessa governança em rede propiciada pelos grupos.
Também se observam nos grupos os aspectos apresentados por Powell (1990) para as redes: indivíduos engajados em ações recíprocas, preferenciais e de apoio mútuo, com unidades (no caso as empresas coordenadoras dos grupos, responsáveis pelas vendas) que não existem por elas mesmas, mas em relação com outras unidades; o grupo é visto como a cola social que mantém as usinas nesse sistema de cooperação e troca de experiências, sobretudo durante as reuniões dos associados (nos casos A e B, com periodicidade semanal). Embora haja a caracterização de governança em rede, é preciso lembrar que os atributos dessas redes não são necessariamente únicos, havendo, sob diferentes combinações e força, elementos presentes em outras formas de governança, conforme previsto por Grandori e Soda (1995).

Outras características da governança em rede destacadas por Powell (1990) podem ser observadas:

- Ao mesmo tempo que há contratos entre usinas e coordenadoras dos grupos, fatores relacionais, derivados de laços de amizade ou interações prévias em associações setoriais, moldam o comportamento dos atores. No caso A, por exemplo, há um código de conduta informal respeitado pelos associados. Nesse mesmo grupo, nem mesmo foi assinado o contrato de adesão por parte de um dos associados entrevistados, mostrando que, apesar de presente, a questão contratual nem sempre é o fator mais importante;

- Além das reuniões periódicas (no caso C com frequência bem menor) para a comunicação entre os membros e entre coordenadora e membros, outros canais de comunicação são utilizados, como e-mail, informativos, ligações telefônicas quase que diárias da mesa de operações para os associados (sobretudo nos casos A e B) e visitas;

- Os conflitos são resolvidos na base do diálogo, havendo certa preocupação reputacional;

Quadro 4. Os grupos de comercialização como governança em rede.

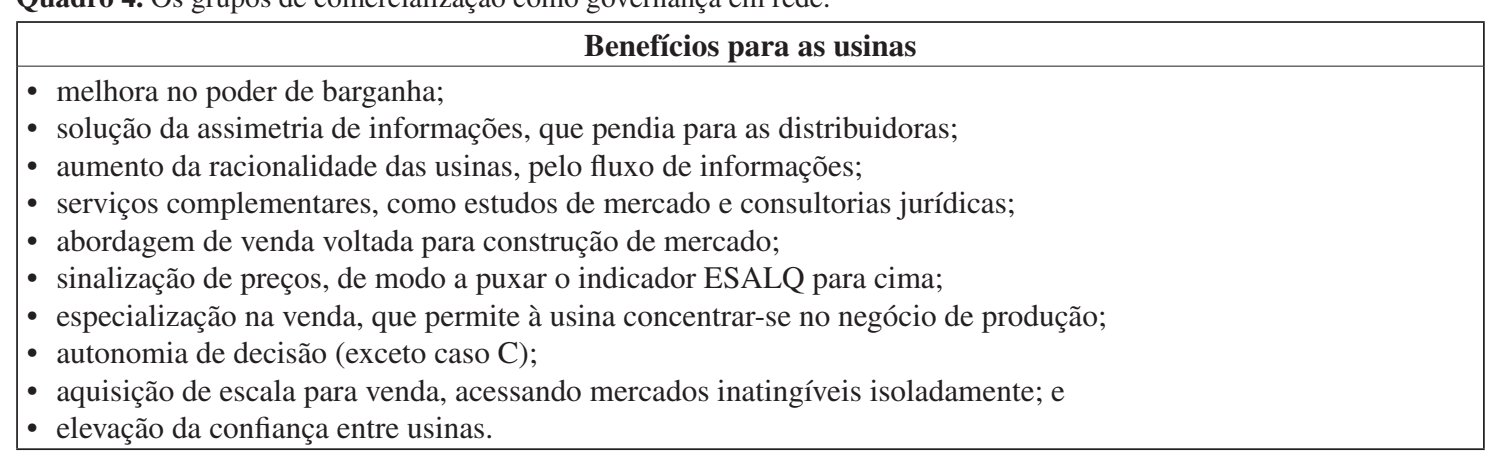

Fonte: Elaborado pelos autores. 
- A flexibilidade é de média a alta, já que, apesar da existência de sinalização interna do grupo quanto a preço para venda e de projetos coletivos que exigem a participação de todos (como o arrendamento de terminal portuário), há autonomia dos membros para decisão (exceção feita pelo caso $\mathrm{C}$, em que a coordenadora concentra o poder de decisão da venda e há ingerência sobre a produção das associadas);

- Mesmo com diferentes graus de envolvimento (alguns associados participam com menor ou maior assiduidade de reuniões), a maior parte dos membros é comprometida;

- O reconhecimento de benefícios mútuos na associação faz com que as usinas demonstrem uma atitude positiva para com o grupo, o que é favorável ao seu clima; e

- A escolha dos atores é interdependente, já que ao mesmo tempo que os grupos buscam atrair novos membros, eles precisam ser aprovados pelos já associados.

As características observadas nos grupos também corroboram as listadas por Jones, Hersterly e Borgatti (1997): um conjunto selecionado, persistente e estruturado de firmas autônomas (as usinas), assim como agências não lucrativas (as empresas coordenadoras dos grupos), engajadas em criar produtos ou serviços (as operações de venda, a elaboração de estudos e, no caso $\mathrm{C}$, também os serviços logísticos), baseados em contratos implícitos e abertos para adaptar às contingências ambientais e coordenar e salvaguardar transações. Sobre a questão da não lucratividade, nos casos $\mathrm{A}$ e $\mathrm{B}$, em que a receita da venda é das usinas, que pagam corretagem à coordenadora, em havendo sobra no período, isso é usado para descontos no período seguinte. No caso C, o lucro é rateado entre os associados.

As características básicas de redes listadas por Assens (2003) foram igualmente constatadas: separação (espacial, territorial) e autonomia dos nós, no caso as usinas, que têm liberdade de ajustar seu comportamento e suas decisões (em menor grau no caso C); interdependência dos nós, que, mesmo heterogêneos, unem-se por um denominador comum: a comercialização do etanol. Vale ressaltar que a questão da heterogeneidade deve ser vista com ressalva, já que, na busca de estabelecer um grupo coeso, há certa homogeneidade entre seus membros, ou no porte e na reputação ou na história e nos valores dos membros. Entre os casos estudados, a heterogeneidade é maior nos grupos B e C.

Os grupos são capazes de solucionar, pelo menos em parte, o trade-off colocado por Williamson (1994), segundo o qual, ao caminhar a governança da hierarquia para o mercado, ganha-se em incentivos, mas perde-se em controle. As usinas, ao manter sua individualidade, concentram-se na produção, que permite eficiência produtiva, fundamental no setor de commodities em que maior lucratividade depende de redução de custos. Ao mesmo tempo, em grupo, elas obtêm benefícios da escala na comercialização, do maior acesso a informações e da especialização no processo de venda. O controle, ainda que parcial no caso dos grupos em que a decisão de venda é da usina, é exercido pelas empresas que coordenam os grupos.

Nas vendas entre as usinas e as distribuidoras, há a presença tanto de contratos de longo prazo quanto de vendas spot. No caso C, por centralizar as transações, o grupo assume também o papel de firmar os contratos com as distribuidoras. Porém, nos outros grupos, os contratos são firmados diretamente entre usinas e distribuidoras, tendo a coordenadora um papel de orientação aos seus associados, negociação dos termos e administração, de modo que os contratos sejam os mais vantajosos possíveis às usinas. Em alguns casos, a negociação é feita incluindo um conjunto de usinas, para, com escala, aumentar o poder de negociação. A coordenadora do grupo de comercialização também pode organizar arranjos para consolidar cargas entre diferentes usinas para vendas de maior volume ou mesmo, durante a administração do contrato, para cobrir quebra de safra de alguma unidade.

$\mathrm{O}$ acesso às informações mercadológicas e a capacidade de análise do setor é fundamental para que os grupos de comercialização sejam bem sucedidos na negociação com as distribuidoras. Isso é confirmado pelas próprias distribuidoras de combustível, segundo as quais, na negociação com os grupos, a venda é mais técnica, com possibilidade de barganha muito menor. Isso ocorre pelo fato do grupo formar uma inteligência de mercado. Soluciona-se, assim, um problema de assimetria de informações (levantada por Azevedo (2001) e Marino e Azevedo (2003) como determinante do poder de barganha). Mesmo assim, entrevistas junto ao setor de distribuição mostraram que também para distribuidoras a formação dos grupos é benéfica, ao profissionalizar as relações, trazendo mais eficiência, por exemplo, em operações logísticas, com agilidade em processos de carregamento.

Foi possível constatar, também, que os grupos conseguem reduzir custos de transação, já que com uma alta frequência nas transações entre as usinas e as coordenadoras e dessas com as distribuidoras, é reduzido o incentivo a ações oportunistas, que representariam um ônus aos associados. A ação oportunista de um prejudicaria a reputação de todo o grupo. Além disso, aumenta-se a racionalidade das usinas e das próprias coordenadoras dos grupos, pelo grande fluxo de informações, e há maior capacidade de adaptação a mudanças, já que, além da troca de experiências entre os associados, o grupo tem consultores contábeis, jurídicos e de gestão à 
disposição das empresas. Esses aspectos, mais o poder de barganha, tinham sido listados como benefícios das redes em trabalho de Gonçalves Junior et al. (2007).

A redução dos custos de transação ocorre também pelo maior fluxo de informações. Além da atuação direta na comercialização, as coordenadoras dos grupos A e B elaboram estudos e permitem a troca de informações diversas entre os associados, o que é bastante favorável para a tomada de decisão por parte das usinas. Especialmente as pequenas usinas não conseguiriam ter uma visão completa do setor se atuassem isoladamente. Os grupos têm, portanto, papel importante na redução das incertezas para as usinas, especialmente em um setor com tamanha volatilidade nos preços. No caso $\mathrm{C}$, este fluxo de informações é menor, já que a decisão de venda não é das usinas.

Voltando à questão da decisão de venda, observa-se que o modelo da BBA/Brasil Álcool de enxugamento de álcool do mercado, com a criação de estoques e destinação para exportação, não consegue ser repetido por todos os grupos, pois o único grupo que tem a decisão de venda é o do caso $\mathrm{C}$. O produtor de etanol, embora receba informações que direcionem para os melhores momentos de venda, não leva em consideração isso se tem dificuldades financeiras; muitas vezes a venda é instantânea à produção. Além disso, há o problema das usinas que vendem por fora do grupo de comercialização, reduzindo a coesão. Portanto, um papel ainda mais relevante do grupo acaba sendo a sinalização para o mercado, criando um cenário para elevação dos preços, de modo a puxar o indicador ESALQ para cima. Atualmente, os quatro principais grupos são referências para a determinação de preços. A soma da participação dos quatro grupos de comercialização na produção de etanol (52\%, conforme DOLNIKOFF, 2008) é próxima à soma da participação das distribuidoras BR, Ipiranga e Raízen (Cosan/Shell) nas vendas de etanol (57\%, conforme AGÊENCIA..., 2010), o que efetivamente auxilia nessa sinalização. Se, para as distribuidoras, a sinalização, ao puxar o preço do etanol para cima, é negativa, ao mesmo tempo evita distorções no setor. Uma das distribuidoras explicou dessa forma: pensando-se na concorrência com outras distribuidoras, em que o custo do combustível é fundamental para colocar nos postos um produto com preço mais atraente ao consumidor, é mais difícil monitorar as transações da concorrência com unidades independentes, do que com os grupos de comercialização, com quem há troca de informações constante. Eventualmente, uma unidade independente pode realizar uma venda para uma distribuidora concorrente com preço abaixo da posição daquela distribuidora, resultando para essa em perda de competitividade em preço. Isso é mais raro com atuação forte dos grupos de comercialização.
Sobre a gestão dos grupos, a presença de uma empresa responsável por administrá-lo, coordenar reuniões, realizar as transações comerciais e solucionar conflitos, faz com que ela (coordenadora) constitua-se em um ator dominante da rede. Assim, os grupos de comercialização de etanol caracterizam redes com alta centralidade. No caso $\mathrm{C}$, esse agente central tem ainda mais força, por concentrar as decisões. Isso é um dos indicativos de governança em rede multifacetada. Como citado, há variação nas formas de organização dos grupos, que podem ser explicadas tanto pela constituição jurídica de cada grupo, como pela sua história e mecanismos de aglutinação.

A maior evidência da governança em rede multifacetada nos grupos de comercialização reside no caso $\mathrm{C}$, que se diferencia dos demais grupos ao: deter a decisão de venda; atuar tanto na venda de etanol quanto de açúcar e subprodutos da cana-de-açúcar; e possuir infraestrutura logística e de escritórios no exterior. O grupo C, inclusive, destoa da definição de rede de Sauvée (2002 apud FARINA; ZYLBERSZTAJN, 2003), segundo a qual, ainda que um centro estratégico pudesse ser identificado, não haveria nas redes uma empresa que concentrasse os direitos de decisão. É justamente a decisão, entre os mecanismos de coordenação listados por Grandori e Soda (1995) que podem levar a diferentes tipos de rede, que faz com que o caso $\mathrm{C}$ mais se diferencie dos demais grupos. Embora esse modelo do caso $\mathrm{C}$ permita coordenar oferta e estoques, algumas empresas não o veem como vantajoso, pelo fato de tirar o poder de decisão da usina e não haver tanto fluxo de informações, limitando a visão do usineiro sobre o setor. Constata-se, portanto, que a problemática do balanceamento entre autonomia individual e controle coletivo, destacada por Assens (2003) como importante para o sucesso de uma rede, está presente nos grupos de comercialização.

A Figura 1 traz uma representação visual comparativa das redes formadas pelos grupos de comercialização. Ressalta-se, inicialmente, que esta é uma representação qualitativa das redes. Não é uma representação exata da densidade e da centralidade das redes a partir da medição das transações entre todos os agentes, pois este não era o objetivo do trabalho. Para isso, seria preciso um estudo quantitativo e o uso de softwares próprios a esta função. Optou-se, aqui, pela realização de um estudo qualitativo que desse conta da complexidade do tema em todo seu contexto, com foco maior nas relações do que na estrutura. A seguir, explicam-se os critérios usados para o desenho das redes.

Quanto maiores os papéis exercidos pela coordenadora na rede, maior a esfera que a representa. No caso das esferas compactas, que representam as usinas associadas, o seu tamanho refere-se ao porte médio dos membros (quanto maior, maior o porte). A quantidade de esferas representando as usinas não 
corresponde exatamente ao número de unidades de cada grupo; no entanto, é proporcional a esse número, de modo a facilitar o desenho da rede e, ao mesmo tempo, permitir comparações quanto à extensão de cada uma. As relações entre usinas e coordenadora do grupo são representadas pelas linhas tracejadas; quanto mais forte o traço (vide caso $\mathrm{C}$ ), maior o grau de formalidade da relação, com amparo em
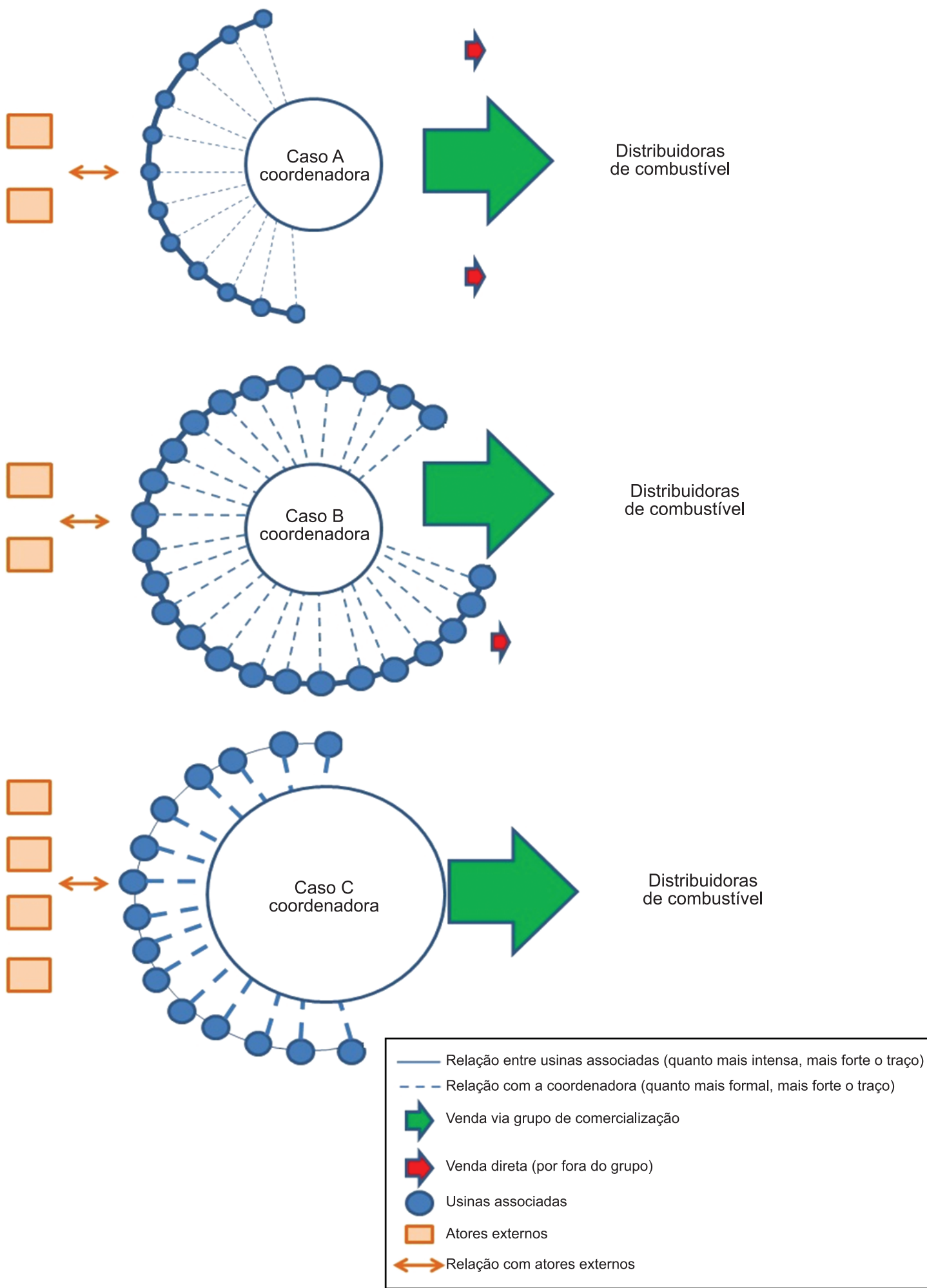

Figura 1. Representação das redes formadas pelos grupos de comercialização. Fonte: Elaborado pelos autores. 
instrumentos jurídicos e monitoramento rigoroso. As linhas contínuas representam as relações entre as associadas, no que se refere à troca de experiências e informações, cooperação e interação; quanto mais forte o traço, mais forte o relacionamento (vide casos A e B). As caixas quadrangulares representam atores externos à rede, como instituições financeiras, investidores e fornecedores. Quanto maior o número de caixas, mais relevantes as conexões externas que o grupo proporciona. Por fim, as setas compactas grandes representam as vendas para as distribuidoras de combustível realizadas via coordenadoras dos grupos de comercialização; as setas compactas pequenas significam a presença de vendas diretas para as distribuidoras, contrariando as cláusulas de exclusividade de comercialização via coordenadora. Quanto maior a presença desse tipo de transação, maior o número de setas vermelhas.

Desta forma, a rede A pode ser caracterizada como a menor em número de associados e, ao mesmo tempo, com associados de menor porte. As relações com a coordenadora têm menor grau de formalização. $\mathrm{O}$ menor porte das usinas provoca, também, um menor volume de transações (operações comerciais) entre usinas e coordenadora. Isto é compensado, por sua vez, por uma forte interação entre as usinas e dessas com a coordenadora, com reuniões semanais dos associados e maior grau de pessoalidade no relacionamento. O menor grau de formalização e a forte interação entre as usinas fazem com que surjam regras tácitas de conduta entre os membros. Porém, não inibem a presença (em maior grau do que nos outros grupos) de vendas diretas de etanol das usinas para as distribuidoras. Por fim, as conexões externas, embora existentes, são muitas vezes redundantes.

$\mathrm{A}$ rede $\mathrm{B}$ é a maior em número de associados e possui associados com maior volume de produção do que a rede A, o que resulta em maior status desses. Há forte interação entre as usinas associadas, igualmente viabilizada por reuniões semanais, que se transformam em fóruns de discussão e cooperação. As relações com a coordenação do grupo têm maior grau de formalização, com contratos renovados a cada safra. Assim como no caso A, a coordenadora operacionaliza as vendas, administra contratos, oferece consultorias e elabora cenários mercadológicos. Embora existam vendas diretas entre usinas e distribuidoras, elas são menos frequentes que no caso A. As conexões externas que o grupo proporciona, assim como no caso $\mathrm{A}$, existem, mas são redundantes.

$\mathrm{A}$ rede $\mathrm{C}$ é aquela em que a coordenadora do grupo concentra maior poder e exerce mais papéis, uma vez que ela concentra as decisões de venda e extrapola sua atuação para a esfera logística. Além disso, há maior ingerência nas usinas, em aspectos como volume e mix de produção. Embora os associados recebam consultorias, há menor fluxo de informações mercadológicas, justamente pelo fato das decisões de venda serem da coordenadora. Esse papel central da coordenadora exige maior formalização nas relações com as usinas, com contratos de associação de longa duração (mínimo de 10 anos) e a existência de mecanismos diversos de monitoramento. Como resultado, não há vendas por fora do grupo de comercialização. As usinas associadas são, em geral, de médio e grande porte, como no caso B. No entanto, as relações entre elas são fracas, já que as reuniões são pouco frequentes, o que acaba por promover pouca interação. Por sua vez, as conexões externas são relevantes, propiciadas, sobretudo, pela coordenadora, com sua grande atuação internacional e o respaldo a operações das associadas com instituições financeiras.

\section{Considerações finais}

Desde o ciclo do açúcar, no período colonial, passando pelo Proálcool e pelo surgimento dos carros flex, o setor sucroalcooleiro alternadamente vivencia tempos áureos e crises, reputação má e ruim. A velocidade das transformações se acentuou na última década, junto com a desregulamentação do setor. Um dos principais fenômenos foi a consolidação, por parte das usinas, da estratégia de venda conjunta, via grupos de comercialização de etanol. À Copersucar juntaram-se SCA, Bioagência e CPA, que até hoje perduram, mudando a forma como se realizam as transações entre o elo indústria-distribuição.

A teoria econômica sobre estruturas de governança tradicionalmente coloca que as transações podem se dar via mercado (vendas spot), firma (integração vertical) ou contratos de longo prazo. O mesmo acontece com os poucos estudos no setor sucroalcooleiro que abordam as transações entre indústria-distribuição, sendo os grupos de comercialização vistos apenas como intermediários. No entanto, a teoria econômica também mostra que formas mais complexas de coordenação, com a presença de indivíduos engajados em ações recíprocas e frequentes, num misto de competição e cooperação, permitem performance superior àquela que seria obtida isoladamente em ambientes com a presença de oportunismo, racionalidade limitada e alta incerteza. Partindo-se desta perspectiva teórica, e considerando o papel cada vez mais relevante dos grupos de comercialização no setor sucroalcooleiro, definiu-se como objetivo da pesquisa mostrar os modos de organização de diferentes grupos de comercialização de etanol e os mecanismos de governança constituídos para venda do produto.

Por meio de um estudo de casos múltiplos com três dos quatro grupos atuantes na região Centro-Sul, constatou-se que os grupos de comercialização, já responsáveis por mais da metade do etanol vendido no Brasil, caracterizam formas de governança em rede. Assim, as empresas coordenadoras de cada 
grupo não se restringem a meras intermediárias das transações entre usinas e distribuidoras. Na verdade, criam uma nova dinâmica, ao proporcionar a seus associados melhor acesso ao mercado, sinalizar preços, organizar arranjos logísticos, negociar e administrar contratos. Muito mais do que um braço comercial das usinas, constituem-se em centro de inteligência de mercado e fórum de discussão e cooperação entre as usinas, até nas esferas agrícolas e industriais. Além disso, as usinas têm à sua disposição serviços de consultoria. Isso aumenta a capacidade de adaptação às transformações do ambiente institucional, tão necessária, dadas as incertezas e turbulências do setor sucroalcooleiro. O estudo mostrou, também, que há uma governança em rede multifacetada, uma vez que os grupos têm características diferentes de organização. Destaca-se, nesse sentido, o grupo C, que, ao contrário dos demais, concentra na coordenadora a decisão de venda e assume operações logísticas.

Como estudos futuros, sugere-se analisar com profundidade os impactos para os setores de produção e distribuição dos recentes acordos estratégicos entre empresas petrolíferas e grandes grupos industriais sucroalcooleiros, tais quais as parcerias da Petrobras com usinas e a joint-venture Cosan/Shell, que criou a Raízen. Nessa linha, o perfil da gestão do setor sucroalcooleiro também pode ser estudado, já que, paralelamente a esses acordos estratégicos e à maior presença de atores internacionais, se percebe maior grau de profissionalização em um setor tradicionalmente familiar. Por fim, observa-se que a formação de redes no setor não se limita à governança das transações com o setor de distribuição. Grupos setoriais para discussão de temas específicos, como recursos humanos e mecanização, são comuns e extrapolam os grupos de comercialização de etanol. A forma de organização desses grupos setoriais e seus resultados merecem análises à luz do institucionalismo econômico e sociológico.

\section{Referências}

AMARAL, T. M.; NEVES, M. F.; MORAES, M. A. D. Cadeias produtivas do açúcar do estado de São Paulo e da França: comparação dos sistemas produtivos, organização, estratégias e ambiente institucional. Agricultura São Paulo, v. 50, n. 2, p. 65-80, 2003.

AGÊNCIA NACIONAL DO PETRÓLEO, GÁS NATURAL E BIOCOMBUSTÍVEIS - ANP. Anuário estatístico brasileiro do petróleo, gás natural e biocombustíveis 2010. Disponível em: <http://www.anp.gov.br/?pg=31286> Acesso em: 10 nov. 2010.

AGÊNCIA NACIONAL DO PETRÓLEO, GÁS NATURAL E BIOCOMBUSTÍVEIS - ANP. Anuário estatístico 2001. Disponível em: <http://www.anp.gov.br/?pg=38591\&m=\&t1 $=\& \mathrm{t} 2=\& \mathrm{t} 3=\& \mathrm{t} 4=\& \mathrm{ar}=\& \mathrm{ps}=\&$ cachebust $=1305155845000 \mathrm{>}$. Acesso em: 05 maio 2011.
ASSENS, C. Le réseau d'entreprises: vers une synthèse des connaissances. Management International, v. 7, n. 4, p. 49-59, 2003.

AZEVEDO, P. F. Nova economia instuticional: referencial geral e aplicações para a agricultura. Revista Agricultura em São Paulo, v. 47, n. 1, p. 33-52, 2000.

AZEVEDO, P. F. Informação e barganha: implicações estratégicas em arranjos verticais. In: SEMINÁRIO BRASILEIRO DA NOVA ECONOMIA INSTITUCIONAL, 2., 2001, Campinas. Anais.. Campinas: Instituto de Economia Unicampa, 2001.

BACCARIN, J. G.; GEBARA, J. J.; FACTORE, C. O. Concentração e integração vertical do setor sucroalcooleiro no Centro-Sul do Brasil entre 2000 e 2007. Informações Econômicas, v. 39, n. 3, 2009.

BALESTRIN, A.; VARGAS, L. M. A dimensão estratégica das redes horizontais de PMEs: teorizações e evidências. Revista de Administração Contemporânea, p. 203-227, 2004. Edição Especial 2004.

BALESTRIN, A.; VARGAS, L. M.; ARBAGE, A. P. A perspectiva dos custos de transação na formação de redes de cooperação. Revista de Administração de Empresas Eletrônica, v. 6, n. 1, 2007.

BARROS, G. Grupos estrangeiros aumentam participação no setor sucroalcooleiro. Disponível em: <http:// colunistas.ig.com.br/guilhermebarros/2010/02/25/ grupos-estrangeiros-aumentam-participacao-no-setorsucroalcooleiro-diz-kpmg/> Acesso em: 16 jul. 2010.

BRITTO, J. Cooperação interindustrial e redes de empresas. In: KUPFER, D.; HASENCLEVER, L. (Org.). Economia Industrial: fundamentos teóricos e práticos no Brasil. 2. ed. Rio de Janeiro: Campus, 2002.

BRYMAN, A. Research methods and organization studies. London: Routledge, 1989. http://dx.doi. org/10.4324/9780203359648

CARVALHO, F. C. et al. Estudo da integração vertical na agroindústria sucroalcooleira no estado de São Paulo, 1970-1992. Agricultura em São Paulo, v. 40, n. 1, p. 157-182, 1993.

CONSOLI, M. H. Fatores influenciadores na decisão de produzir ou comprar: um estudo no sistema agroindustrial da cana. 2007. Dissertação (Mestrado em Ciências Contábeis e Financeiras)-Pontifícia Universidade Católica de São Paulo, São Paulo, 2007.

DOLNIKOFF, F. Contratos de etanol carburante e racionalidade econômica da relação entre usinas e distribuidoras de combustíveis no Brasil. 2008. Dissertação (Mestrado em Administração)-Faculdade de Economia, Administração e Contabilidade da Universidade de São Paulo, São Paulo, 2008.

FARINA, E.; ZYLBERSZTAJN, D. Economics of networks and patterns of competition in food and agibusiness. Faculdade de Economia, Administração e Contabilidade, USP, 2003. Working Paper, n. 03/027.

GONÇALVES JUNIOR, C. A. et al. A formação de redes horizontais à luz da Nova Economia Institucional: um estudo de caso. In: ENCONTRO DE ECONOMIA PARANAENSE, 5., 2007, Curitiba. Anais... Curitiba: UFPR, 2007.

GRANDORI, A.; SODA, G. Inter-firm networks: antecedents, mechanisms and forms. Organization 
Studies, v. 16, n. 2, p. 183-214, 1995. http://dx.doi. org/10.1177/017084069501600201

JANK, M. Uma matriz de combustíveis para o Brasil. In: SOUZA, E. L.; MACEDO, I. C. (Org.). Etanol e bioeletricidade: a cana-de-açúcar no futuro da matriz energética. São Paulo: LUC, 2010. p. 10-13.

JARILLO, J. C. On strategic networks. Strategic Management Journal, v. 9, n. 1, p. 31-41, 1988. http://dx.doi.org/10.1002/smj.4250090104

JONES, C.; HERSTERLY, W.; BORGATTI, S. P. A general theory of network governance: exchange conditions and social mechanisms. Academy of Management Review, v. 22, n. 4, p. 911-945, 1997.

LOPES, M. B. Análise dos canais de distribuição do etanol carburante brasileiro: um estudo exploratório. 2009. Dissertação (Mestrado em Engenharia de Produção)Universidade Federal de São Carlos, São Carlos, 2009.

MATOS, V. A.; MELO, P. C. L.; MATOS, P. J. A teoria dos custos de transação e a coordenação no sistema canavieiro. In: ENCONTRO NACIONAL DE ENGENHARIA DE PRODUÇÃO, 9., 1999, Rio de Janeiro. Anais... Rio de Janeiro: ENEGEP, 1999.

MARCON, M.; MOINET, N. La stratégie-réseau. Paris: Éditions Zéro Heure, 2000.

MARCHI, J. J.; WITTMANN, M. L. Redes de empresas: uma análise das relações entre fatores sócio-comportamentais e desempenho competitivo. Revista Eletronica de Administração, ed. 60, v. 14, n. 2, 2008.

MARINO, M. K.; AZEVEDO, P. F. Avaliação da intervenção do sistema brasileiro de defesa da concorrência no sistema agroindustrial da laranja. Revista Gestão \& Produção, v. 10, n. 1, p. 35-46, 2003.

MAZZALI, L.; COSTA, V. M. H. M. As formas de organização "em rede": configuração e instrumentos de análise da dinâmica industrial recente. Revista de Economia Política, v. 17, n. 4, p. 121-139, 1997.

MELLO, F. O. T. As metamorfoses da rede de poder agroindustrial sucroalcooleira no estado de São Paulo: da regulação estatal para a desregulamentação. 2004. Dissertação (Mestrado em Engenharia de Produção)Universidade Federal de São Carlos, São Carlos, 2004.

MÉNARD, C. Le pilotage des forme organisationnelles hybrids. Revue Economique, v. 48, p. 741-750, 1997.

MÉNARD, C. The economics of hybrid organizations. Journal of Institutional and Theoretical Economics, v. 160, p. 345-376, 2004. http://dx.doi. org/10.1628/0932456041960605

MÉNARD, C. A new institutional approach to organization. In: MENARD, C.; SHIRLEY, M. (Eds.). Handbook of New Institutional Economics. 2005. p. 281-318.

MORI, J. S.; MORAES, M. A. F. D. Características do mercado do álcool anidro e hidratado e suas implicações para o mercado de combustíveis. In: CONGRESSO BRASILEIRO DE ECONOMIA E SOCIOLOGIA RURAL, 45., 2007, Londrina. Anais... Londrina: SOBER, 2007.

NEVES, M. F.; WAACK, R. S.; MARINO, M. K. Sistema agroindustrial da cana-de-açúcar: caracterização das transações entre empresas de insumos, produtores e usinas. In: CONGRESSO BRASILEIRO DE ECONOMIA E SOCIOLOGIA RURAL, 36., 1998, Poços de Caldas. Anais... Brasília: SOBER, 1998.
PAULILlO, L. F. O.; MELLO, F. O. T.; VIAN, C. E. F. Análise da competitividade das cadeias de agroenergia no Brasil. In: BUANAIN, A. M.; BATALHA, M. O. (Coords.). Análise da competitividade das cadeias agroindustriais brasileiras. São Carlos: DEP-UFSCar; IE-UNICAMP, 2006.

PAUlillo, L. F. O.; VIAN, C. E. F.; MELlO, F. O. Autogestão, governança setorial e sustentabilidade no complexo agroindustrial canavieiro no século 21 . Revista de Política Agrícola, n. 1, p. 40-62, 2008.

PAULILLO, L. F. O. et al. Álcool combustível e biodiesel no Brasil: quo vadis? Revista de Economia e Sociologia Rural, v. 45, n. 3, 2007. http://dx.doi.org/10.1590/ S0103-20032007000300001

PODOLNY, J. M.; PAGE, K. L. Networks forms of organization. Annual Review Sociology, v. 24, n. 1, p. 57-76, 1998. http://dx.doi.org/10.1146/annurev. soc. 24.1 .57

POWELL, W. W. Neither market nor hiearchy: network forms of organization. Organizational Behavior, v. 12, p. 295-336, 1990.

POWELL, W. W.; SMITH-DOERR, L. Networks and economic life. In: SMELSER, N.; SWEDBERG, R. (Org.). Handbook of Economic Sociology. Princeton: Princeton University Press, 1994.

SACOMANO NETO, M.; TRUZZI, O. M. S. Configurações estruturais e relacionais de fornecedores: uma resenha compreensiva. Revista de Administração da USP, v. 39, n. 3, p. 255-263, 2004.

SCOTT, W. R. Institutions and organizations. Thousand Oaks: SAGE, 2001.

SIQUEIRA, P. H. L.; CASTRO JUNIOR, L. G. C. Fusões e aquisições das unidades produtivas e da agroindústria de cana-de-açúcar no Brasil e nas distribuidoras de álcool hidratado etílico. Revista de Economia e Sociologia Rural, v. 48, n. 4, 2010.

SOUZA, J. V. P. Sistemas agroindustriais e formas organizacionais: estudo de caso no SAG do café e SAG do açúcar e álcool. Ribeirão Preto: FEA RP, USP, 2004.

UNIÃO DOS PRODUTORES DE BIOENERGIA - UDOP. Oeste Paulista e MS se unem e criam novo canal de comercialização de etanol. UDOP, 2008. Disponível em: <http://www.udop.com.br/index. php? $\operatorname{cod}=1052488 \&$ item $=$ noticias $>$. Acesso em: 12 mai. 2009.

VALOR ECONÔMICO. Cresce concentração na venda de álcool. São Paulo: Economia, 2009.

VIAN, C. E. F. Agroindústria canavieira: estratégias competitivas e modernização. Campinas: Editora Átomo, 2003.

VIAN, C. E. F.; LIMA, A. A.; LIMA, R. A. S. Estudo de impacto econômico para o setor agroindustrial canavieiro paulista e alagoano: conjuntura e agenda de pesquisa. Revista Econômica do Nordeste, v. 39, p. 518-539, 2008.

VIAN, C. E. F.; PAULILLO, L. F. O.; BELIK, W. Evolução das formas de coordenação do mercado de álcool e açúcar no Brasil: da intervenção estatal à formação dos campos organizacionais. In: CONGRESSO DA SOCIEDADE BRASILEIRA DE ECONOMIA, ADMINISTRAÇÃO 
E SOCIOLOGIA RURAL, 46., 2008, Rio Branco. Anais... Rio Branco: SOBER, 2008.

VOSS, C.; TSIKRKTSIS, N.; FROHLICH, M. Case research in operations management. International Journal of Operatoins \& Production Management, v. 22, n. 2, p. 195-219, 2002. http://dx.doi. org/10.1108/01443570210414329
WILLIAMSON, O. E. The economic institutions of capitalism. New York: Free Press, 1985.

WILLIAMSON, O. E. Transaction cost economics and organization theory. In: SMELSER, N. J.; SWEDBERG, R. (Eds.). The handbook of economic sociology. Princeton: Princeton University Press, 1994. p. 77-107. 